\title{
Chromatographic appraisal of fatty acid profile in camel's milk at different temperatures
}

\author{
Zabih Ullah Aamir ${ }^{1}$, Hamayun Khan ${ }^{2}$, Said Wahab ${ }^{1}$, Muhammad
} Tarique Tunio ${ }^{3}$, Haq Amanullah ${ }^{2 *}$, Omme Aimen ${ }^{4}$, Shah Murad Khan ${ }^{5}$ and Kamal Shah ${ }^{6}$

1. Department Food Science and Technology, the University of Agriculture, Peshawar 25130, Khyber

Pakhtunkhwa-Pakistan

2. Department of Animal Health the University of Agriculture, Peshawar 25130, Khyber Pakhtunkhwa-Pakistan

3. Department of Agricultural Sciences, Allama Iqbal Open University, Islamabad-Pakistan

4. Veterinary Research and disease investigation centre, Ratha Kulachi, D.I. Khan-Pakistan

5. Livestock and Dairy Development, Khyber Pakhtunkhwa-Pakistan

6. Faculty of Veterinary and Animal sciences, Gomal University D.I. Khan, Khyber Pakhtunkhwa-Pakistan

*Corresponding author's email: drhaqamanullah@aup.edu.pk

Citation

Zabih Ullah Aamir, Hamayun Khan, Said Wahab, Muhammad Tarique Tunio, Haq Amanullah, Omme Aimen, Shah Murad Khan and Kamal Shah. Chromatographic appraisal of fatty acid profile in camel's milk at different temperatures. Pure and Applied Biology Vol. 8, Issue 2, pp1069-1076. http://dx.doi.org/10.19045/bspab.2019.80048

Received: 09/01/2019

Revised: 22/03/2019

Accepted: 28/03/2019

Online First: 04/04/2019

\section{Abstract}

Milk is an important component of humans' diet. Milk fats provide the essential fatty acids important for health and normal growth of the body. The aim of the study was to determine the fatty acid profile of camel's milk through gas chromatography mass spectrometry (GC-MS) at different temperatures i.e. $4^{\circ} \mathrm{C}, 7^{\circ} \mathrm{C}$, and $16^{\circ} \mathrm{C}$. A total of 18 milk samples were obtained from lactating local camels available in Peshawar, Pakistan. The results demonstrated a higher proportion of saturated fatty acids (SFA) than unsaturated fatty acids (USFA) in milk samples. The predominant fatty acids were Palmitic acid (C16:0), Myristic acid (C14:0) and Stearic acid (C18:0), where they were $48.86 \%, 23.5 \%$ and $15.26 \%$ of the total fatty acids in milk respectively. The SFA were dominated by Myristic acid (C14:0) and Palmitic acid (C16:0) and the major monounsaturated fatty acids (MUFA) were Heptadecenoic (C17:1) and Eicosanoic acid (C20:1) and the major polyunsaturated fatty acid (PUFA) was Linoleic acid (C18:2c). The Medium-chain fatty acids (MCFA) which was represented by Lauric acid (C12:0) only was $1.51 \%$ in milk. The current study further elucidated differential expression of diverse fats with temperature changes. The statistical analysis showed that Myristic acid (C14:0), Pentadecanoic acid (C15:0), Palmitoleic acid C16:1c, Stearic acid (C18:0), and Linoleic acid $(\mathrm{C} 18: 2 \mathrm{c})$ varied significantly $(\mathrm{p}<0.05)$ in response to change in temperature.

Key words: Camel; Chromatography; Fatty acids; Milk

\section{Introduction}

Milk is one of the most significant foods for human beings containing lactose, protein, fat, vitamins and minerals in simple, digestible and acceptable form. It is regarded as complete diet for pregnant mothers and 
young children [1]. According to recent statistic of the Food and Agriculture Organization, the entire population of camel in the world is approximately 20 million and Somalia has the leading herds worldwide [2]. Camel is regarded as an excellent resource of meat and milk. All the vital nutrients present in bovine milk are found in camel milk [3]. Record shows that a good fed camel yield 10$15 \mathrm{~L}$ milk per day. In desert areas and those regions where there is scarcity of fodder, camels yield an average of $4 \mathrm{~L}$ milk per day [4]. Camel is regarded as an excellent resource of meat and milk. It is also used for many other activities including transport purpose, racing and dancing. The nutrition of peoples existing in the dry hot regions mainly depends on camel milk. In Saudi Arabia, camel's milk is mostly common and is taken as fresh and sour milk [5]. The countries including Russia, Sudan and India generally use fresh and fermented camel's milk for the treatment different diseases such as tuberculosis, jaundice, dropsy, leishmaniasis (kala-azar) and asthma [6].

Records show that keeping quality of camel's milk is better than cow milk, because of its absolute protein content which has antibacterial effects making it a profitable product [7]. Camel milk is more heat resistant due to its antimicrobial agents when compared with that of cow and buffalo milk [8]. The difference between camel's milk and milk produced by other animals is that it has lower level of sugar, protein and cholesterol but increased levels of insulin, vitamins and minerals [9]. The milk of camel contain 86.3 to $88.5 \%$ water, 8.9 to $14.3 \%$ solid-non-fat, 2.9 to $5.8 \%$ lactose, 2.9 to $5.5 \%$ fat, 2.5 to $4.5 \%$ protein and 0.35 to $0.90 \%$ ash [10]. The composition of lipids are cholesterol $(\mathrm{C}$, $0.5 \%$ ), phospholipids (PL, 0.8\%) and triacylglycerol (TG, 98\%). In the aqueous phase of milk the globules of lipids (3-5\%) are present in emulsified form [11]. Based on the chemical structures, lipids can be categorized into many classes [12]. The lipid class which is found mostly is triacylglycerol (TAG) leaving behind phospholipids. Despite the aforementioned facts regarding camel milk composition, comprehensive appraisal of the lipid profile of camel milk has not been fully reported. Accordingly, attempt has been made here to elucidate the fatty acid profile of camel milk and determine milk fat percentage at different temperatures.

Materials and methods Collection of milk samples

A total of 18 milk samples $(150 \mathrm{ml}$ each $)$ were collected in sterilized bottles from the local lactating camels in District, Peshawar. These camels are easily found throughout the province. Samples were shifted to laboratory in ice box to maintain the cold chain during transportation. The milk samples were divided into three portions under sterile condition. The 1 st portion stored at $4^{\circ} \mathrm{C}$, the $2^{\text {nd }}$ stored at $7^{\circ} \mathrm{C}$ while the $3^{\text {rd }}$ portion stored at $16^{\circ} \mathrm{C}$. Samples stored at $4^{\circ} \mathrm{C}$ were analyzed at three-week interval, sample stored at $7^{\circ} \mathrm{C}$ at two-week interval while sample stored at $16^{\circ} \mathrm{C}$ were analyzed on day 0 .

\section{Lipid profile determination}

The lipid profile was determined through GC-MS (QP-2010, Shimadazu, Japan, $\mathrm{ID}=\mathrm{PLC} / \mathrm{FTC} / \mathrm{Chem}, \mathrm{MB} / 05$ ) at Pakistan Council of Scientific and Industrial Research (PCSIR) Laboratories, Peshawar, according to the optimized protocol [13].

\section{Extraction}

Briefly, $30 \mathrm{ml}$ milk sample was added into $112.5 \mathrm{ml}$ Chloroform-Methanol solution (1:2 $\mathrm{v} / \mathrm{v}$ ) in a $300 \mathrm{ml}$ conical flask and vortexed the mixture for 2 min., followed by centrifugation with $37.5 \mathrm{ml}$ chloroform and vortexed the mixture again for $2 \mathrm{~min}$. Distilled water $(37.5 \mathrm{ml})$ was added into mixture and vortexed, followed by centrifugation at $1000 \mathrm{RPM}$ for five min at room temperature. The mixture was separated into two layers (aqueous at top and organic at the bottom). The sample was 
evaporated (Rotavapour, Japan) after careful removal of bottom layer through pasture pipette without disturbing the upper phase.

\section{Fatty acids methyl ester (FAME) preparation}

Fatty acids methyl ester was prepared for GC-MS analysis according to the standard procedure [14]. Briefly $20 \mathrm{ml}$ sample in a test was added with $1.5 \mathrm{ml}$ of $0.5 \%$ solution of sodium hydroxide $(\mathrm{NaOH})$ and boiled for 5 min. It was followed by addition of Borontrifluoride-methanol $\left(\mathrm{BF}_{3}-\mathrm{CH}_{3} \mathrm{OH}\right) 2.5$ $\mathrm{ml}$, saturated solution of Sodium Chloride $(\mathrm{NaCl}) 5 \mathrm{ml}$ and $1 \mathrm{ml}$ Hexane (twice), each for specific time in the sample test tube. At the last upper layer was removed and FAME tubes were closed tightly and kept in refrigerator.

\section{GC-MS conditions}

The composition of Fatty acid methyl ester was determined by using Shimadzu, gas chromatograph mass spectrometer (model GC-MS QP 2010. plus Japan) having electron impact detector. Helium gas was used as carrier having a linear velocity of $65.8 \mathrm{~cm} / \mathrm{sec}$. The column temperature was held at $50^{\circ} \mathrm{C}$ for $1 \mathrm{~min}$ and was increased at a rate of $5^{\circ} \mathrm{C}$ to $150^{\circ} \mathrm{C}$. Then it was kept constant at $175^{\circ} \mathrm{C}$ for $5 \mathrm{~min}$ and finally increased to $220^{\circ} \mathrm{C}$ at the rate of $10^{\circ} \mathrm{C} / \mathrm{min}$ and was held for $5 \mathrm{~min}$. The injector and ion source temperature was maintained at $240^{\circ} \mathrm{C}$ and $250^{\circ} \mathrm{C}$ respectively. The inter face temperature was kept at $240^{\circ} \mathrm{C}$ on scan mode with $\mathrm{M} / \mathrm{z}$ from 85 to 380 . Standard mixtures of identified fatty acids were used for the determination of peaks and compared the retention time of unknown sample with standard for identification of fatty acids.

\section{Determination of fat $\%$ in milk}

Determination of fat $\%$ was carried out by standard protocol of Gerber method of fat determination in milk. Briefly, $11 \mathrm{ml}$ milk sample, $10 \mathrm{ml}$ sulfuric acid $(85 \%)$ and $1 \mathrm{ml}$ amyl alcohol were mixed in butyrometer, and closed with rubber cork. The mixture was centrifuged in Gerber centrifuge machine at $1100 \mathrm{rpm}$ for $5 \mathrm{~min}$. The butyrometer scale determined the total fat $\%$.

\section{Statistical analysis}

Data were statistically analyzed by applying Complete Randomized Design (CRD) and means were compared by using LSD test at $5 \%$ level of significance [15].

\section{Results and discussion}

Total of 11 fatty acids of different saturation levels were detected in milk samples (Table 1). Out of 11, six were saturated (SFA) and five were unsaturated fatty acids (USFA). The major SFA were Myristic acid (C14:0) and Palmitic acid (C16:0) and the major MUFA were Heptadecenoic (C17:1) and Eicosanoic acid (C20:1) and the major PUFA was Linoleic acid (C18:2c). The predominant fatty acids were Palmitic acid (C16:0), Myristic acid (C14:0) and Stearic acid (C18:0), where they formed 48.86\%, $23.5 \%$ and $15.26 \%$ of total fatty acids in milk, respectively. These findings are in close association with [16], who found that Palmitic acid (C16:0), Myristic acid (C14:0) and Stearic acid (C18:0) were major fatty acids in concentration $31.5 \%, 12.5 \%$, and $12.5 \%$ respectively. The findings of [6], showed that camel milk has $26.6 \%$ Palmitic acid (C16:0), 10.1\%Myristic acid (C14:0) and $12.2 \%$ Stearic acid (C18:0) respectively. The Medium-chain fatty acids (MCFA) represented by a sole member Lauric acid (C12:0) was $1.51 \%$ in milk. These results are against the findings of [17], who reported that Lauric acid (C12:0) accounts in the range of 0.35 to $0.41 \%$. This could be due to difference in feed intake by the camel and to difference in breeds, geographic locality, lactation stage and the environment [18]. The omega $6(\mathrm{~N}-6)$ fatty acids Linoleic acid (C18:2c) and g-linolenic acid (C18:3n6) formed $1.39 \%$ and $0.29 \%$ of total fatty acids in milk respectively. These findings are also similar to the results of [17]. 
Table 1. Concentration (\%) of different fatty acids in camel's milk

\begin{tabular}{|c|c|}
\hline Fatty acids & Concentration (\%) \\
\hline Lauric acid (C12:0) & 1.51 \\
\hline Myristic acid (C14:0) & 23.25 \\
\hline Pentadecanoic acid (C15:0) & 3.28 \\
\hline Palmitic acid (C16:0) & 48.86 \\
\hline Palmitoleic acid C16:1c & 0.17 \\
\hline Margaric acid C17:0 & 1.59 \\
\hline Heptadecanoic acid (C17:1) & 3.93 \\
\hline Stearic acid (C18:0) & 15.26 \\
\hline Linoleic acid (C18:2c) & 1.39 \\
\hline g-Linolenic acid (C18:3n6) & 0.29 \\
\hline Eicosenoic acid (C20:1) & 0.41 \\
\hline
\end{tabular}

The proportions for saturated (SFA), monounsaturated fatty acids (MUFA), and polyunsaturated fatty acids (PUSFA) were $93.75 \%, 4.53 \%$, and $1.68 \%$, respectively (Table 2). Compared to the present results different contents of $(66.1 \%)$ saturated fatty acids and $(30.5 \%)$ unsaturated fatty acids were reported in camel milk [19]. This could be due to difference in feed intake by the camel and to difference in breeds, geographic locality, lactating stage and the environment [18]. Fatty acids and cholesterol contents in camel milk of Bactrian, dromedary and hybrids from different regions of Kazakhstan, within different seasons were determined. Fatty acids composition greatly varied in different regions [18]. The short chain fatty acids C6:0 and C8:0 were not detected in the samples of the current study. These findings are similar to the results of another study [20], who reported that even by decreasing the column temperature to $140^{\circ} \mathrm{C}$, the short chain fatty acids such as 6:0 and 8:0 were not detected in camel milk sample. It was concluded [16] that short chain fatty acids of camel milk are less than $1.2 \%$. Other scientists [21] studied that factors such as animal genetics, feed, seasonal e and regional effects can effect fatty acid composition of an animal. Even-numbered long-chain saturated fatty acids (Myristic acid C14:0, Palmitic acid C16:0 and Stearic acid C18:0) in camel milk accounts for $87.37 \%$ of total fatty acids, with Palmitic acid C16: 0, Stearic acid C18: 0 and Myristic acid C14: 0 the most important components, respectively. These results are closely related with the findings of $[6,22]$. Palmitic acid (C16:0) was the major fatty acid and it accounted for $48.86 \%$ of the saturated fatty acids found in camel milk. These findings are in close association with [23], who reported that Palmitic acid (C16:0) accounts for $49.7 \%$ of the saturated fatty acids in adult camel milk.

Table 2. Concentration of fatty acids groups (\%) in camel milk

\begin{tabular}{|c|c|}
\hline Fatty acids groups & Concentration \% \\
\hline Total fatty acids (TFA) & $99.96 \%$ \\
\hline Saturated fatty acids (SFA) & $93.75 \%$ \\
\hline Mono unsaturated fatty acids (MUFA) & $4.53 \%$ \\
\hline Poly unsaturated fatty acids (PUFA) & $1.68 \%$ \\
\hline
\end{tabular}

In the present study, the fatty acid concentration showed variation with change in temperature. The mean values for Lauric acid, Palmitic acid, Margaric acid, Heptadecanoic acid, g-Linolenic acid, and Eicosanoic acid at temperatures $16^{\circ} \mathrm{C}, 7^{\circ} \mathrm{C}$, 
and $4{ }^{\circ} \mathrm{C}$ showed non-significant $(\mathrm{p}<0.05)$ variation (Table 3, Figure 1, 2, 3). These results are in close association with the findings of earlier researchers [23, 24]. Results showed significant $\quad(\mathrm{p}<0.05)$ variations in concentration of Myristic acid,
Pentadecanoic acid, Palmitoleic acid, and Linoleic acid with changing temperature level (Table 3). These results are similar to the findings reported by earlier scientists [23, 24].

Table 3. Fatty acid composition of camel milk (\%) at various temperatures $\left(16^{\circ} \mathrm{C}, 7^{\circ} \mathrm{C}\right.$ and 4 C)

\begin{tabular}{|c|c|c|c|c|}
\hline Fatty acids & $\begin{array}{c}\text { Mean value at } \\
16^{\circ} \mathrm{C}\end{array}$ & $\begin{array}{c}\text { Mean value at } \\
7^{\circ} \mathrm{C}\end{array}$ & $\begin{array}{c}\text { Mean value at } \\
4^{\circ} \mathrm{C}\end{array}$ & P value \\
\hline Lauric acid (C12:0) & 1.51 & 1.59 & 1.51 & 0.0525 \\
\hline Myristic acid (C14:0) & 23.25 & 24.07 & 24.66 & 0.0149 \\
\hline Pentadecanoic acid (C15:0) & 3.28 & 3.37 & 3.58 & 0.0293 \\
\hline Palmitic acid (C16:0) & 48.86 & 47.76 & 46.70 & $\mathrm{NS}$ \\
\hline Palmitoleic acid C16:1c & 0.17 & 0.12 & 0.11 & 0.0424 \\
\hline Margaric acid C17:0 & 1.59 & 1.64 & 1.74 & $\mathrm{NS}$ \\
\hline Heptadecanoic acid (C17:1) & 3.93 & 4.32 & 4.09 & $\mathrm{NS}$ \\
\hline Stearic acid (C18:0) & 15.26 & 14.83 & 15.26 & 0.0131 \\
\hline Linoleic acid (C18:2c) & 1.39 & 1.60 & 1.59 & 0.0467 \\
\hline g-Linolenic acid (C18:3n6) & 0.29 & 0.28 & 0.29 & $\mathrm{NS}$ \\
\hline Eicosenoic acid (C20:1) & 0.41 & 0.43 & 0.48 & $\mathrm{NS}$ \\
\hline
\end{tabular}

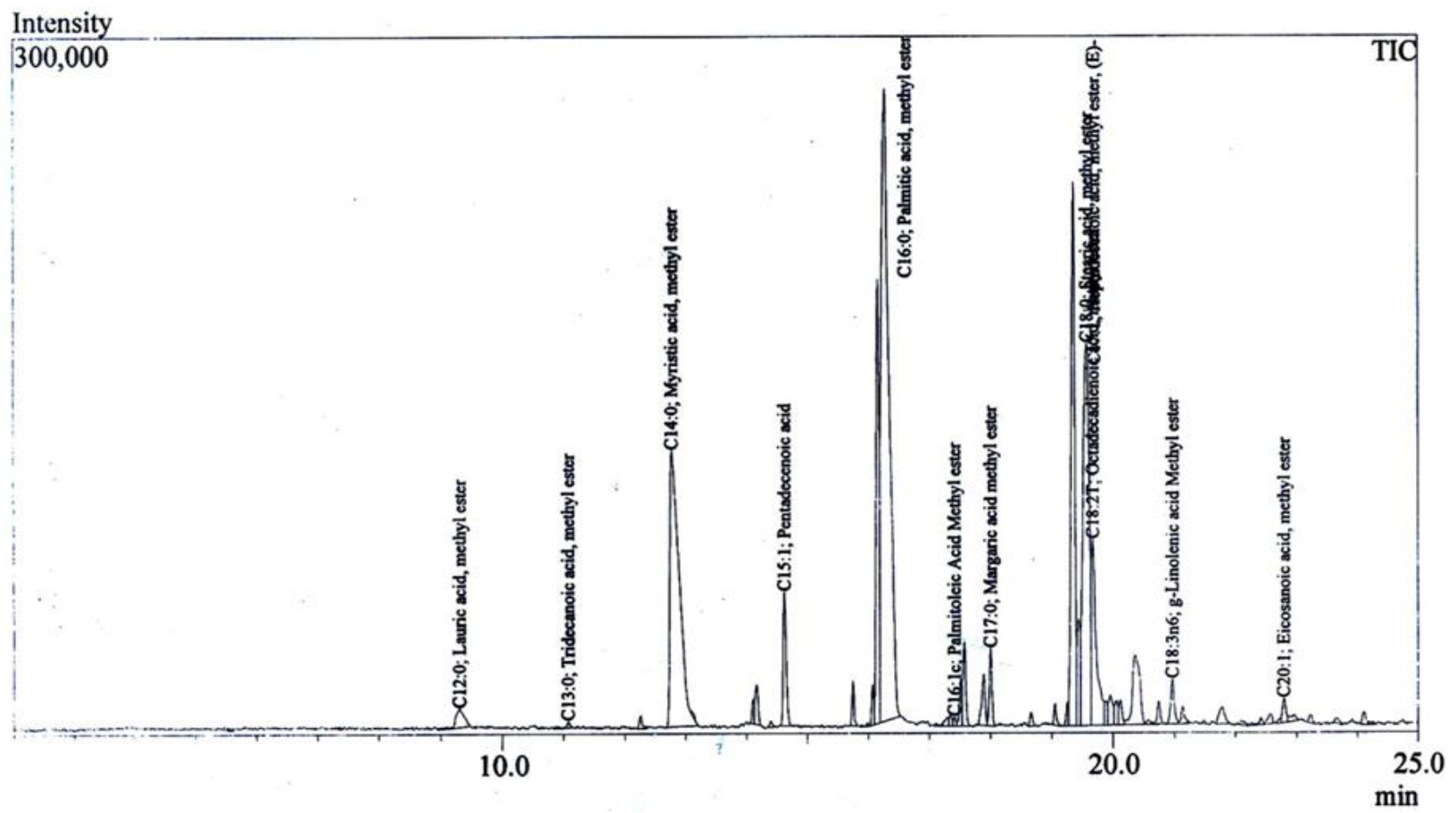

Figure 1. Gas chromatogram of camel milk fat at $16^{\circ} \mathrm{C}$. 


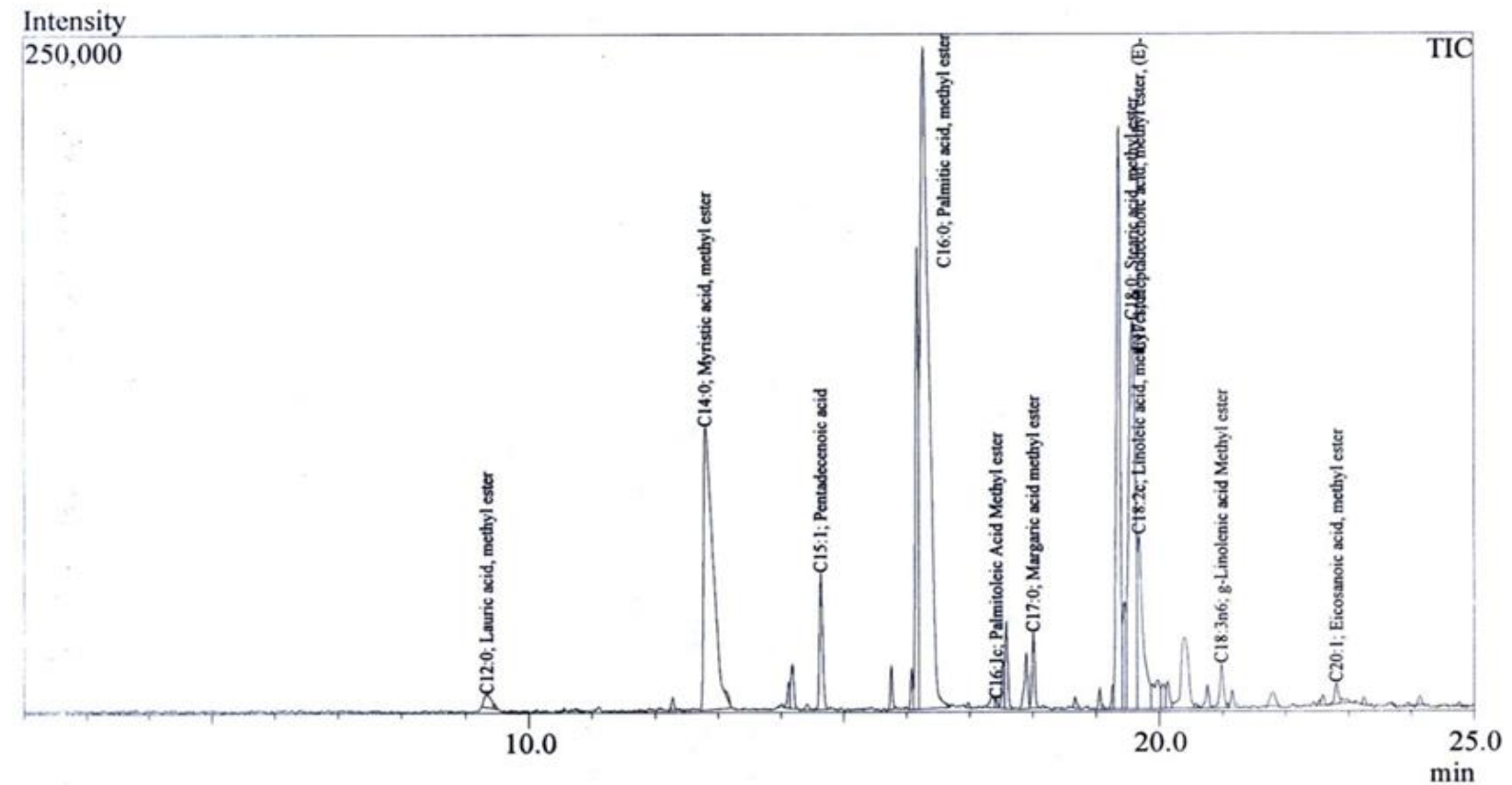

Figure 2. Gas chromatogram of camel milk fat at $7^{\circ} \mathrm{C}$

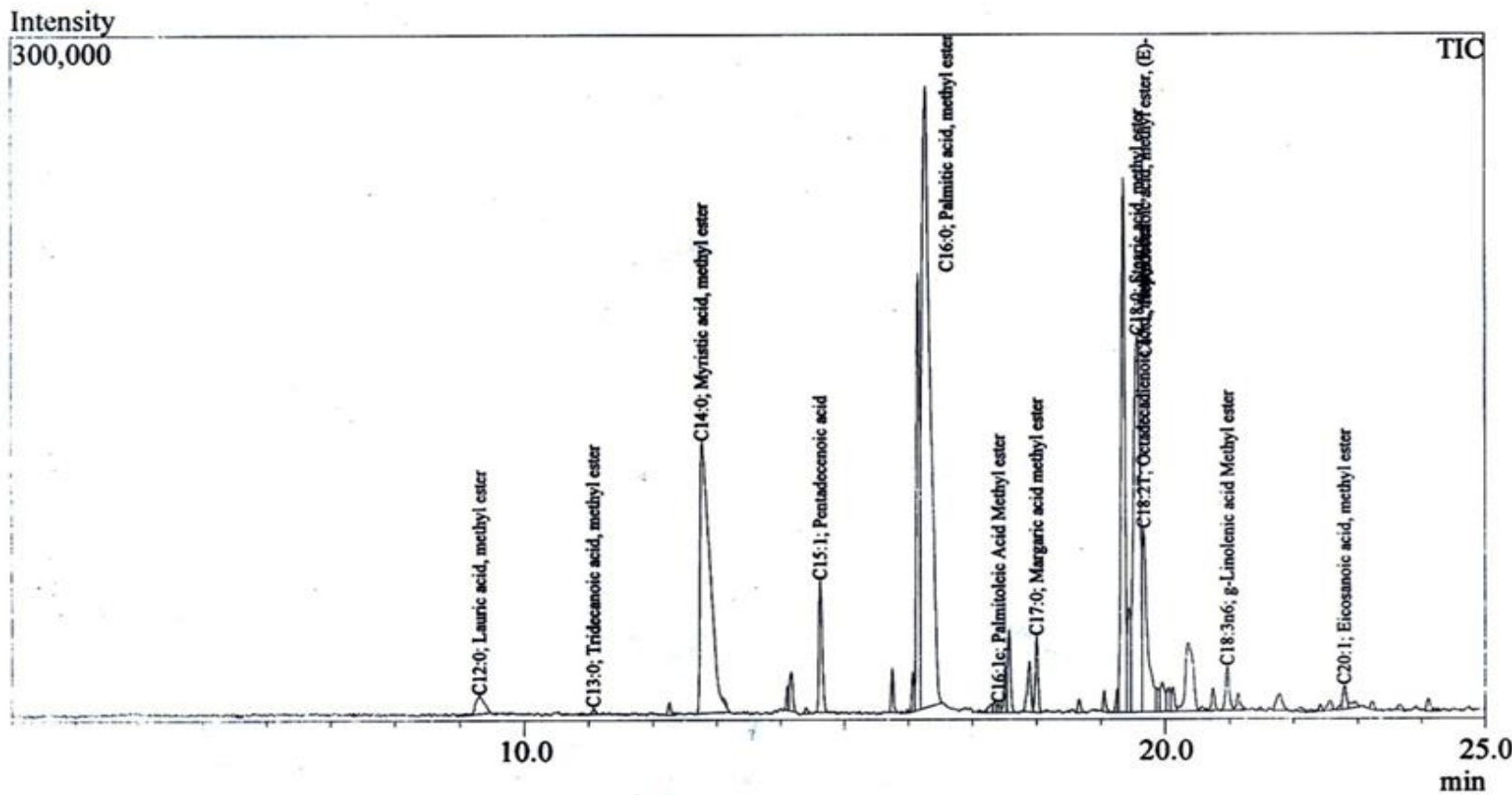

Figure 3. Gas chromatogram of camel milk fat at $4{ }^{\circ} \mathrm{C}$

\section{Conclusion}

In conclusion, camel milk is having a higher proportion of saturated fatty acids than unsaturated fatty acids. The current study further elucidated differential expression of diverse fats with changing temperature. The statistical analysis showed that Myristic acid (C14:0), Pentadecanoic acid (C15:0), Palmitoleic acid C16:1c, Stearic acid (C18:0), Linoleic acid (C18:2c) 
concentration change significantly $(\mathrm{p}<0.05)$ in response to change in temperature.

\section{Authors' contributions}

Conceived and designed the experiments: ZU Aamir, H Khan \& S wahab, Performed the experiments: ZU Aamir, Analyzed the data: S Wahab, MT Tunio, O Aimen \& SM Khan, Contributed materials/ analysis/ tools: S Wahab, SM Khan \& K Shah, Wrote the paper: H Amanullah \& H Khan.

\section{Acknowledgments}

Authors gratefully acknowledge Pakistan Council of Scientific and Industrial Research (PCSIR) Laboratories, Peshawar, for providing laboratory facilities for the current research work.

\section{References}

1. Shah SK \& Khan SA (1982). Factors influencing the protein level in milk. Progressive Farming 2: 10-13.

2. FAO (2008). Camel milk. Retrieved from

http://www.fao.org/ag/againfo/themes/e $\mathrm{n} /$ dairy/camel.html.

3. Karue CN (1998). The dairy characteristics of the Kenyan camel. In: Bonnet, P. (Ed.), Actes du colloque, Dromadairesetchameaux, animauxlaitiers/Dromedaries and Camels, Milking Animals. CIRAD Publishing. Nouakchott. Mauritania, pp 55-60.

4. Yasin SA, \& Wahid A (1998). Pakistani camels: a preliminary survey. Pak J Agri Res 8: 289-297.

5. Abu-Tarboush HM \& Ahmed SB (2005). Characterization of hydrolysates produced by enzymatic of camel casein and protein isolates of Al-Ban (Moringaperegrina) and Karkade (Hibiscus sabderiffa) seeds. J Saudi Soci Agric Sci 2: 61-81.

6. Abu-Lehia IH (1989). Physical and chemical characteristics of camel milk fat and its fractions. Food Chem 34: $261-272$.
7. Yaqoob M \& Nawaz H (2007). Potential of Pakistani camel for dairy and other uses. Anim Sci J 78: 467-475.

8. Shamsia SM, Agamy EI, El-Ghanam M \& Zina H (2008). Buffalo milk proteins. I. Immunological characterization. In: Biovision Alexandria Conference, 1114 April, Bibliotheca Alexandrina, Alexandria, Egypt.

9. Yousef MI (2004). Aluminum-induced changes in hematobiochemical parameters, lipid peroxidation and enzyme activities of male rabbits: protective role of ascorbic acid. Toxicology 199: 47-57.

10. Khan BB \& Iqbal A (2001). Production and composition of camel milk, Review. Pak J Agri Sci 38: 64-68.

11. Jensen RG (1996). The Lipids in Human Milk. Prog Lipid Res 35: 53-92.

12. Fahy E, Subramanian S, Brown HA, \& Glass CK (2005). A comprehensive classification system for lipids. J Lipid Res 46: 839-861.

13. Bligh EG, \& Dyer WJ (1959). A Rapid method of total lipid extraction and purification. Canad J Biochem Phys 37: 911-917.

14. Morrison WR \& Smith LM (1964). Preparation of fatty acid methyl ester and dimethylocelates from lipid with boranfloride-methanol. Department of food Sci-Tech Uni of California. Davis. J lip Res 5: 38-46.

15. Steel R \& Torrie J (1997). Mathematical Statistic, 2nd edition. pp. 101-303.

16. Farah Z (1993). Composition and characteristics of camel milk. J Dairy Res 60: 603-626.

17. Mohamed E \& Mustafa A (2013). Fatty Acids Content in Milk of Dromedary Camel (Camelusdromedarius) from Farming and Pastoral Systems in Sudan. Inter J Sci Res 6: 382-390.

18. Konuspayeva G, Faye B, Loiseau G, Ivashehenko A, Meldebkova A \& 
Davletov S (2009). Physiological change in camel milk composition, 1- Effect of lactation stage, Trop Anim Health Prod 42: 495- 499.

19. Gorban AM \& Izzeldin OM (1999). Study on cholesteryl ester fatty acids in camel and cow milk lipid. Int J Food Sci Tech 34: 229-234.

20. Gorban AM \& Izzeldin OM (2001). Fatty acids and lipids of camel milk and colostrum. Int J Food Sci Nut 52: 283 287.

21. Palmquist DL, Beaulieu AD \& Barbano DM (1993). Feed and animal factors influencing milk fat composition. $J$ Dairy Sci 76: 1753-1771.
22. Sawaya WN, Khalil JK, Al-Shalhatand A, \& Al-Mohammad H (1984). Chemical composition and nutritional quality of camel milk. J Food Sci 49: 744-747.

23. Regula A, Boncaza $\mathrm{G} \&$ Pustkowiak $\mathrm{H}$ (2005). The effect of heat treatment on the free fatty acid in ewe milk. Biotech Anim Hus 21: 237-240.

24. Salamon R, Mándoki Z, Csapó-Kiss Z, Gyori A, Gyori Z \& Csapó J (2009). Changes in fatty acid composition of different milk products caused by different technology. Alimentaria 2: 101-109. 